\title{
Pelvic organ prolapse and uterine preservation: a survey of female gynecologists (POP-UP survey)
}

Peter Urdzík ${ }^{1 *} \mathbb{0}$, Vladimir Kalis ${ }^{2,3}$, Mija Blaganje ${ }^{4}$, Zdenek Rusavy ${ }^{2,3}$, Martin Smazinka ${ }^{3}$, Martin Havir ${ }^{3}$, Rastislav Dudič ${ }^{1}$ and Khaled M. Ismail ${ }^{2,5}$

\begin{abstract}
Background: The aim of this study was to explore the personal views of female gynecologists regarding the management of POP with a particular focus on the issue of uterine sparing surgery.

Methods: A questionnaire based survey of practicing female gynecologists in the Czech Republic, Slovenia and Slovakia.

Results: A total of 140 female gynecologists from 81 units responded to our questionnaire. The majority of respondents stated they would rely on a urogynecologist to aid them with their choice of POP management options. The most preferred options for POP management were sacrocolpopexy and physiotherapy. Almost 2/3 of respondents opted for a hysterectomy together with POP surgery, if they were menopausal, even if the anatomical outcome was similar to uterine sparing POP surgery. Moreover, $81.4 \%$ of respondents, who initially opted for a uterine sparing procedure, changed their mind if the anatomical success of POP surgery with concomitant hysterectomy was superior. Discussing uterine cancer risk in relation to other organs had a less significant impact on their choices.
\end{abstract}

Conclusions: The majority of female gynecologists in our study opted for hysterectomy if they were postmenopausal at the time of POP surgery. However, variation in information provision had an impact on their choice.

Keywords: Preference, Survey, Attitude, Prolapse, Hysterectomy, Sparing surgery

\section{Background}

One in 9 women undergo a form of reconstructive surgery for pelvic organ prolapse (POP) during the course of their life and this is expected to increase with the prolongation in life expectancy [1]. With improving operative safety and anesthetic techniques, such surgical procedures are more frequently performed on perimenopausal and postmenopausal women [2-5]. Indeed, in a study by Kalis et al. [6], 108 (89.3\%) of 121 women undergoing

\footnotetext{
${ }^{*}$ Correspondence: peter.urdzik@upjs.sk

1 Department of Gynecology and Obstetrics, Faculty of Medicine, Safarik's University and L. Pasteur Teaching Hospital in Kosice, SNP Street No. 1, 04001 Košice, Slovak Republic

Full list of author information is available at the end of the article
}

laparoscopic sacrocolpopexy were $>50$ years. Until recently, vaginal hysterectomy was the most common operation in POP management $[7,8]$. The main proposed reasons for removal of the uterus were to obtain access to the supporting pelvic structures and/or to reduce the size of the prolapsed mass [9]. Nevertheless, the uterus itself seems to play only a passive role in the etiology of prolapse $[10,11]$ and therefore its removal without a thorough discussion with the patient, about the pros and cons of doing so, may be considered clinically substandard and unethical as it disregards the women's autonomy and basic right of informed choice [12-14]. This issue is exacerbated by the paucity of long-term data on the psychological impact of hysterectomy on women [15]. 
Several studies $[14,16,17]$ have explored women views about the issue of uterine preservation versus concomitant hysterectomy at the time of reconstruction procedures for POP. The heterogeneity in these studies' findings is not unexpected given the impact of several factors including the individual's values, cultural beliefs, level of education, ethnicity, age and family pressure [16, 18-20]. However, in these studies the target population did not specifically have prior medical knowledge hence their decision could have been biased not only by the information provision but rather by how they interpret such information. This is particularly relevant because, in essence, they are making a decision to remove a healthy organ based on projected assumed risks [14, 16, 21]. In order to mitigate the risk of such bias while ensuring that the woman's perspective is taken into account, we decided to target a cohort of women with specialist knowledge in the field of gynecology in general and urogynecology in particular. In this study we undertook a survey of female gynecologists from different European countries with the aim of exploring their personal views about different aspects of management of POP. We also wanted to particularly focus on their choice of whether to preserve the uterus or not in response to different clinical scenarios.

\section{Methods}

The study was undertaken between January and December of 2018 and involved 120 departments of Gynecology and Obstetrics located in the Czech Republic, Slovenia and Slovakia. A national coordinating center (NCC) located in each of the participating countries managed the study elements in that country. The NCCs were based at the Departments of Gynecology and Obstetrics Safarik's University and L. Pasteur Teaching Hospital (SULPTH), University Hospital in Pilsen (UHP) and University Medical Centre Ljubljana (UMCL) in Slovakia, Czech Republic and Slovenia respectively. Anonymized questionnaires were sent by email from the lead investigator of each of the NCCs (UP, KV, BM) to the heads of departments of all the obstetrics and gynecology units in their relevant countries. They were asked to cascade them as hard copies to practitioners who fulfilled a set of a priori specifications. Completed questionnaires were returned by post to the relevant NCC for data extraction. The study received ethical approval from the relevant ethics committee at Ethics committee at L. Pasteur Teaching Hospital in Košice in Slovakia (No. 2020/EK/04024). While UHP in Czech Republic (waiver-April 30, 2020) and UMCL in Slovenia (waiver-April 22, 2018) committees waived ethical approval because of the nature of the study.

\section{Participants, inclusion and exclusion criteria}

Participants were hospital-based female specialist obstetricians and gynecologists who have completed their postgraduate training and working as generalists or subspecialists in obstetrics and gynecology.

\section{Variables}

We used a bespoke questionnaire based on previously published study exploring women's perception of hysterectomy and attitudes towards uterine preservation at the time of POP reconstructive surgery [16]. The questionnaire was distributed in the native language of each of the participating countries (the questionnaires in the participating countries native languages are available on request, the questionnaire in English language-see in Additional file 1). Demographic details collected included participants' age, country of residence, type of hospital they work at, sub-specialization or main area of special interest (materno-fetal medicine, oncogynecology, urogynecology, reproductive medicine, others, no sub-specialty). We also asked about future fertility plans using a 4-point Likert scale ranging from "not at all" to "I definitely will".

Participants were asked to assume they are postmenopausal healthy women, with no prior major gynecological surgeries, suffering from a significant POP involving all compartments (i.e. anterior, apical, posterior), participants were then asked to respond to a set of questions and hypothetical scenarios to explore the following issues:

- Resources or people they would consult to aid them with the decision making about the best treatment for their POP.

- Their preferred type of management for their POP.

- The importance of the uterus to them.

- Potential factors that can affect their decision to have a hysterectomy.

- How important is anatomical outcome on their choice about concomitant hysterectomy with POP surgery.

- Would presenting life-long risk of uterine cancer in the context of other organ cancers impact their decision about choice of procedure?

\section{Statistical methods}

Sample characteristics were summarized using descriptive statistics. Where relevant exact McNemar, Fischer tests and chi-squared test were performed using IBM SPSS Statistics 21.0 and Stata/SE 11.1 (StataCorp LP, College Station, TX, USA) statistical softwares. The cut-off for statistical significance was set at $p<0.05$. 


\section{Results}

\section{Sample description}

Of the 120 approached departments, questionnaires were returned from 81 (67.5\%) of them. A total of 140 female gynecologists completed the questionnaire with a mean age of 38.7 years (range $28-67$ years). Of these, $84(60.0 \%), 31(22.1 \%)$ and $25(17.9 \%)$ were from the Czech Republic, Slovakia and Slovenia respectively. Participants were based at university or teaching hospitals $(\mathrm{n}=82,58.6 \%)$, regional hospitals $(\mathrm{n}=39,27.8 \%)$ and district hospitals $(\mathrm{n}=19,13.6 \%)$. All participants were fully specialized gynecologists, of these 23 (16.4\%) were fetomaternal, 16 (11.4\%) urogynecology and 4 (2.9\%) oncogynecology subspecialists. With regard to future fertility plans, 49 participants $(35.0 \%)$ stated that they completed their family while the remaining 91 (65.0\%) either partially or not at all.

\section{Information provision}

Based on the requested assumed scenario that participants were healthy, postmenopausal, with no prior gynecological surgeries and suffering with a significant POP involving all compartments, relying on a urogynecologist as a source of information was chosen by $130(92.9 \%)$ of the participants as the main information resource. While searching the medical literature, consulting their partner or colleague was chosen by 54 (38.6\%), $24(17.1 \%)$ and $14(10.0 \%)$ of the respondents respectively. Ten participants only have indicated that they would also seek assistance from online resources $(n=6$,
$4.3 \%)$, a female friend ( $\mathrm{n}=3,2.1 \%)$ or an oncogynecologist $(n=1,0.7 \%)$.

\section{Management preference}

Using the same assumption above, participants were asked to rate their likelihood of choosing different management options for POP on a 4-point Likert scale which was later dichotomized to "yes", for definitely and likely, and "no", for not likely and not at all (Fig. 1). The options favored by respondents, when combining definitely and likely responses, were sacrocolpopexy and physiotherapy. While a Manchester repair, no treatment, colpocleisis, and the use of a pessary were the least favored amongst female gynecologists.

\section{Factors impacting decision about hysterectomy}

Participants were asked about their views regarding the importance of various factors on their decision to opt for or decline a hysterectomy, during POP reconstructive surgery, if both were feasible options. Professionals' opinion and risk of surgical complications were considered important by $100 \%$ and $99 \%$ of respondents respectively. The list of factors assessed ranked in order of their importance based on participants' responses are demonstrated in Fig. 2.

When asked about their personal perception about the importance of the uterus for their sense of self, 79/136 (58.1\%) of respondents did not support this view. Of the 57 female gynecologists considering the uterus to be important for their sense of self, 33 (57.9\%) said they

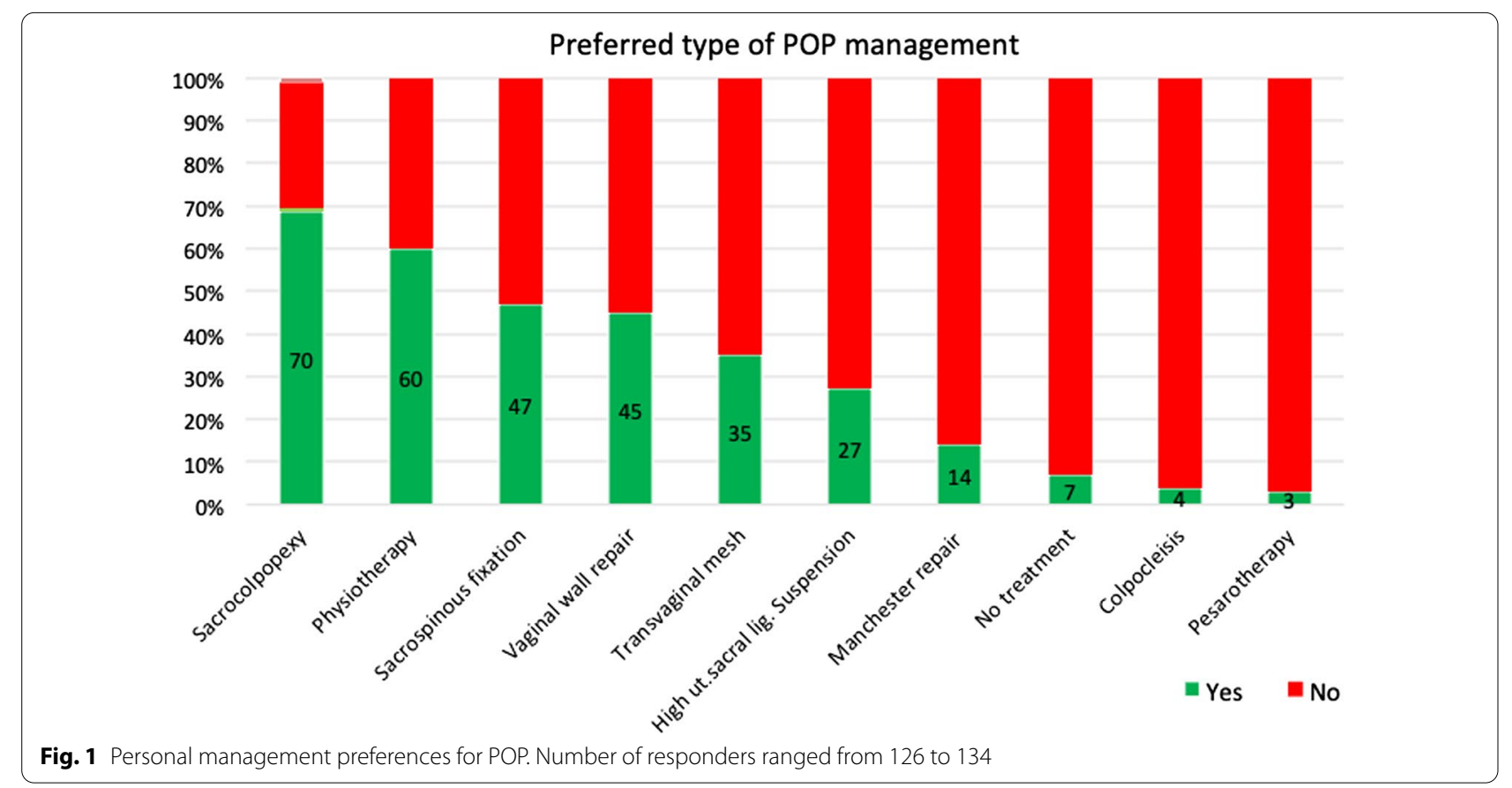


Importance of factors affecting decision regading hysterectomy

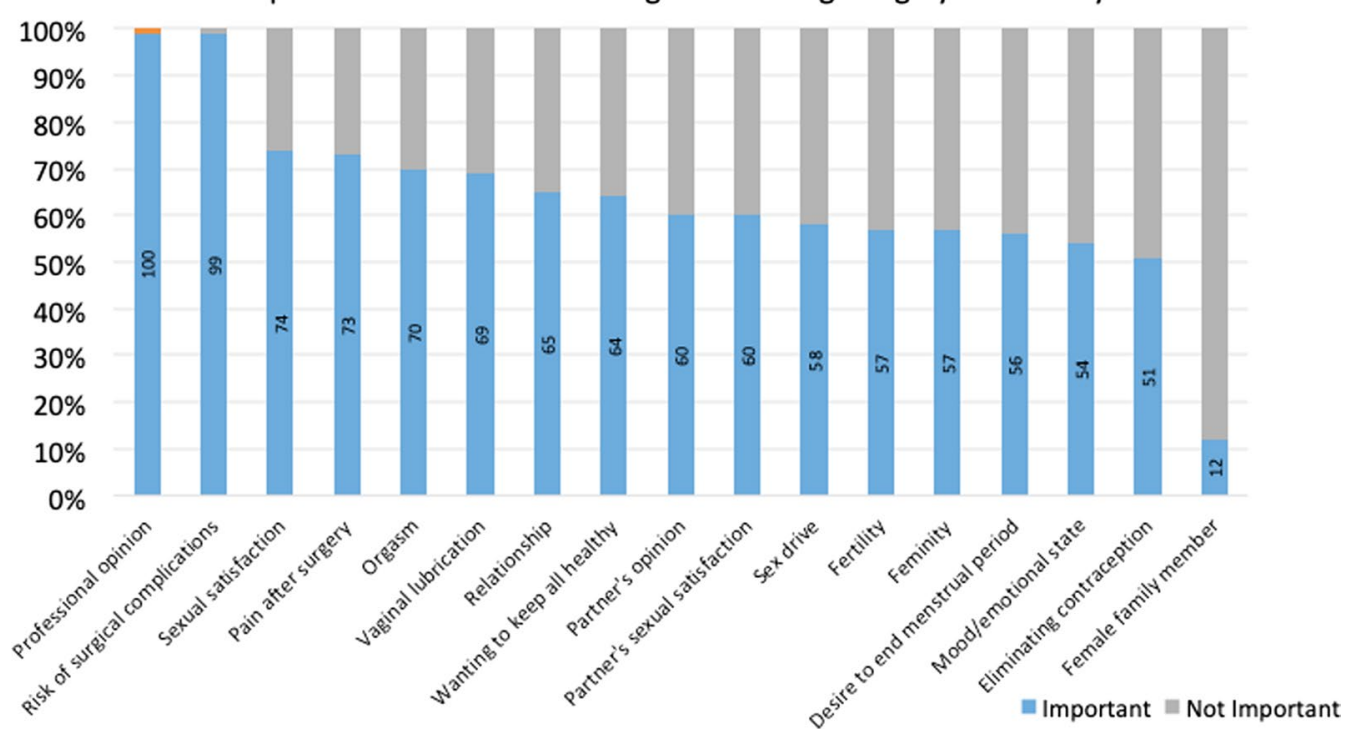

Fig. 2 Importance of factors for decision to undergo or refuse hysterectomy. Number of responders ranged from 133 to 138

would opt for a uterine sparing surgery than a hysterectomy compared to 18 of the $79(22.8 \%)$ who did not support this view $(\mathrm{OR}=4.66, p<0.05)$.

\section{Impact of clinical outcome and risk of cancer on choice of surgery}

When participants were asked about choice of surgery if there was evidence to suggest that anatomical outcomes following POP surgery with uterine sparing were similar to concomitant hysterectomy, 82/125 (65.6\%) still opted for a concomitant hysterectomy. When asked about their choice if there was evidence that uterine sparing is associated with slightly worse outcomes, 35/43 (81.4\%) who initially opted for uterine sparing changed their mind to a concomitant hysterectomy (Fig. 3).

When information on actual background potential risk of uterine cancer in relation to other types of cancers in females was provided while still assuming equal effectiveness of uterine sparing and concomitant hysterectomy POP procedures, 5 (6.1\%) women changed their decision from hysterectomy to uterus sparing surgery and $6(13.9 \%)$ women from uterus sparing surgery to hysterectomy (Fig. 4). Additionally, 122 (87.1\%) respondents stated that they would need to know the recent cervical screening result and 93 (66.4\%) to have a transvaginal ultrasound assessment of their endometrial thickness preoperatively to enable them to make a well informed decision regarding hysterectomy or uterus sparing procedure. The choice of surgery depending on the different scenarios by country is presented in Table 1 .

\section{Discussion}

Summary of results

This study presents personal views of female gynecologists on the issue of POP management with a particular focus on their choice of whether to preserve the uterus or not in response to different hypothetical clinical scenarios. The vast majority of our study participants stated they would rely on a urogynecologist as the main source of information to aid them with their choice of POP management options while, $4.3 \%$ and $0.7 \%$ only, would use online resources or seek the advice of an oncogynecologist, respectively, to help them make a decision.

The most preferred options for POP management were sacrocolpopexy and physiotherapy. Almost $2 / 3$ of female gynecologists who responded to our questionnaire opted for a hysterectomy together with POP surgery, if they were menopausal, even if the anatomical outcome was similar to uterine sparing POP surgery. Moreover, $81.4 \%$ of respondents, who initially opted for a uterine sparing procedure, changed their mind if the anatomical success of POP surgery with concomitant hysterectomy was superior. Significantly more respondents changed their mind from uterine preservation to hysterectomy when asked to consider that uterine sparing might be associated with a slightly more negative clinical outcome compared to when asking them to consider their uterine cancer risk ( $8 / 43$ vs. $35 / 43, p=0.000)$.

\section{Comparison to current literature}

The majority (65.6\%) of female gynecologists would opt for hysterectomy if they were postmenopausal at 


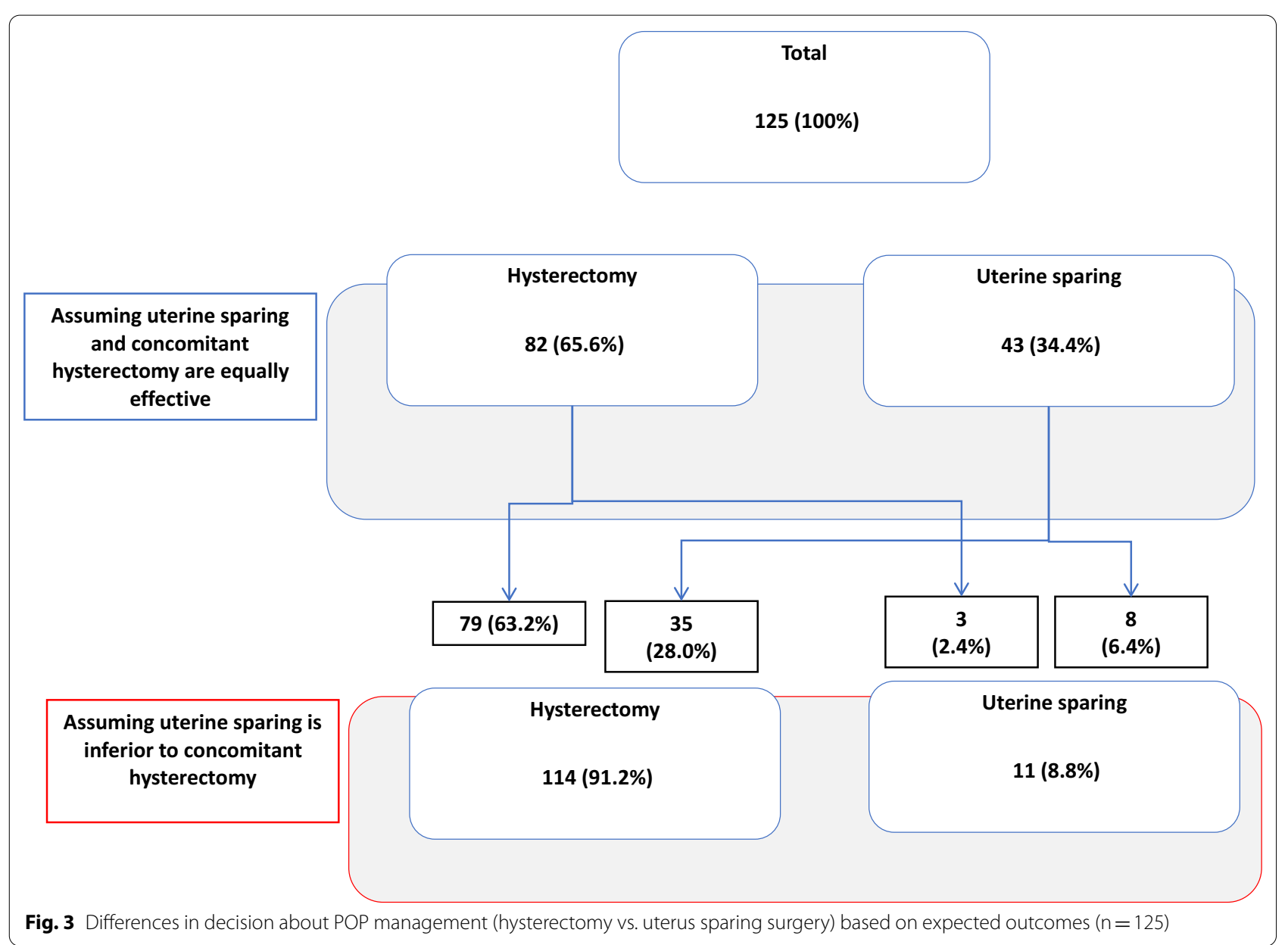

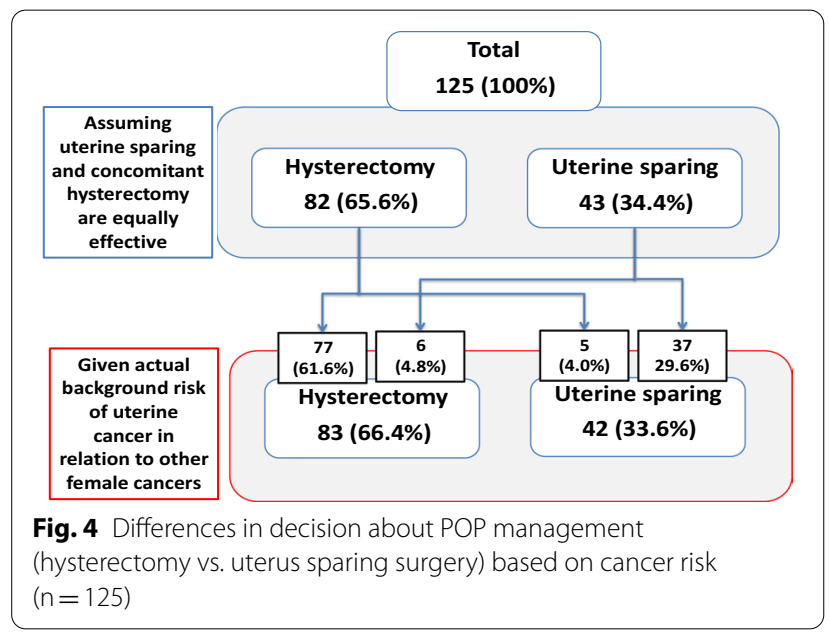

the time of POP surgery, a proportion higher than that reported from previous women surveys whose participants were not recruited because of a particular professional background $[16,17]$.
Limited research exists that assesses patient knowledge of POP treatment options and attitudes regarding hysterectomy and its association with their perception of sexuality, femininity and womanhood [18, 22-24]. Nevertheless, it is the general opinion that the two crucial determinants of the patients' choice of POP surgical technique are the woman's personal views about uterine preservation and the surgeon's procedure preference based on their training and expertise $[25,26]$. It is interesting to see that the majority of specialist female gynecologists seem to prefer a hysterectomy even when quoted similar anatomical success or when highlighting the proximity in life-time uterine cancer risk to other organs. The impact of this issue is more relevant when considering that our respondents are clinicians who can be counseling patients rather than as a woman considering her own options.

Our findings concur with other groups, [14, 27, 28], where we demonstrated that the issues of the impact of a hysterectomy on femininity, sex drive and sexual satisfaction, either for the woman or her partner, did not seem to be a priority in the decision-making process 
Table 1 Impact of clinical outcome and risk of cancer on choice of surgery by country

\begin{tabular}{|c|c|c|c|c|c|c|c|}
\hline \multirow[t]{2}{*}{ Scenario } & \multicolumn{3}{|c|}{ Hysterectomy } & \multicolumn{3}{|c|}{ Uterine preservation } & \multirow[t]{2}{*}{$p$} \\
\hline & $\begin{array}{l}\text { SK } \\
\mathrm{n}=31\end{array}$ & $\begin{array}{l}C Z \\
n=84\end{array}$ & $\begin{array}{l}\mathrm{SL} \\
\mathrm{n}=25\end{array}$ & $\begin{array}{l}\text { SK } \\
n=31\end{array}$ & $\begin{array}{l}C Z \\
n=84\end{array}$ & $\begin{array}{l}\mathrm{SL} \\
\mathrm{n}=25\end{array}$ & \\
\hline $\begin{array}{l}\text { If there was evidence to suggest that anatomical outcomes follow- } \\
\text { ing POP surgery with uterine sparing were similar to concomitant } \\
\text { hysterectomy }\end{array}$ & $18(58.1 \%)$ & $52(61.9 \%)$ & $12(48.0 \%)$ & $13(41.9 \%)$ & $24(28.6 \%)$ & $6(24.0 \%)$ & 0.59 \\
\hline $\begin{array}{l}\text { If there was evidence that uterine sparing is associated with slightly } \\
\text { worse outcomes }\end{array}$ & $26(83.9 \%)$ & $72(85.7 \%)$ & $16(64.0 \%)$ & $5(16.1 \%)$ & $4(4.8 \%)$ & $2(8.0 \%)$ & 0.19 \\
\hline $\begin{array}{l}\text { Provided with information on the actual background potential risk of } \\
\text { uterine cancer in relation to other types of cancers in females }\end{array}$ & $20(64.5 \%)$ & $51(60.7 \%)$ & $12(48.0 \%)$ & $11(35.4 \%)$ & 25 (29.8\%) & $6(24.0 \%)$ & 0.96 \\
\hline
\end{tabular}

SK Slovakia, CZ Czech Republic, SL Slovenia

$p<0.05$ (Chí-squared test)

regarding hysterectomy at time of POP surgery. However, the impact of hysterectomy on clinical outcomes seemed to be an important factor when choosing the optimal procedure. Similar to those of Korbly et al. [14] and van IJsselmuiden et al. [17] the number of women opting for uterine sparing surgery in our study significantly reduced if this was associated with slightly inferior anatomical outcomes (34.4-8.8\%; OR 11.6, $p<0.001)$. A large RCT comparing uterine preservation surgery versus vaginal hysterectomy for POP repair reported similar anatomical and functional outcomes at 12-months [29]. In our survey sacrocolpopexy was the most preferred surgical procedure amongst female gynecologists. This is not surprising given the high-level evidence indicating that abdominal and laparoscopic sacrocolpopexy achieve better anatomical outcomes compared to other surgical options [30]. Several studies compared laparoscopic hysteropexy against total or subtotal hysterectomy with sacrocolpopexy with conflicting results [31-34]. Nonetheless, randomized comparisons of outcomes following sacrocolpopexy with or without uterine preservation are needed. Furthermore, it would also be prudent to explore alternative techniques and modifications that can overcome any variation in outcome [35]. This will ensure that women have two realistic and equal options to choose from. It is also important that women have access to specialized multidisciplinary expertise and validated instruments to help them evaluate their needs and hence make an individualized informed choice about their management [24].

\section{Strengths and limitations}

We appreciate that our study has some limitations including the inability to know the exact number of specialists who received the questionnaire to be able to calculate an accurate response rate. Therefore, it is difficult to assess the risk of selection bias in this survey. However, the fact that our participants are specialized professionals working in different types of units from 3 different countries is reassuring that our sample is representative of the views of female gynecologists currently working in Central Europe. Moreover, the mean age of our participants was 38.7 years and several of them have not completed their families, yet they were asked to base their responses on the hypothetical assumption that they were postmenopausal. It could be argued that the views presented in this study might not be a true reflection of what postmenopausal female gynecologist would do. Nonetheless, it still reflects, to a large extent, what their perception is about the optimal modality of management for a postmenopausal healthy woman. This is of particular importance because of the potential impact this might have on others if we consider their roles as clinicians and trainers. In contrast, the fact that this is the first survey exploring views of female gynecologists about POP management and their preferences about uterine sparing or not is a major strength to our work.

\section{Conclusion}

Concomitant hysterectomy rather than uterine sparing seems to be the preferred option for the majority of female gynecologists if they were to have POP reconstructive surgery. Urogynecologists were deemed the most important resource for our respondents when making a decision about the optimal management of their POP. Moreover, postoperative clinical outcome was an important determinant in their decision about the uterine fate. Therefore, there is an urgent need for information about the short and long-term clinical and patient-reported outcomes of uterine sparing versus concomitant hysterectomy POP surgery to enable women make an informed choice of the best management for them. 


\section{Supplementary information}

Supplementary information accompanies this paper at https://doi. org/10.1186/s12905-020-01105-3.

Additional file 1. Pelvic Organ Prolapse and Uterine Preservation: A survey of female gynecologists (POP-UP survey).

\section{Abbreviations}

POP: Pelvic organ prolapse; NCC: National coordinating center; SULPTH: Safarik's University and L. Pasteur Teaching Hospital; UHP: University Hospital in Pilsen; UMCL: University Medical Center Ljubljana; SK: Slovakia; CZ: Czech Republic; SL: Slovenia.

\section{Acknowledgements}

Not applicable.

\section{Authors' contributions}

PU Literature search, Project development, Project administration, Manuscript writing. VK Literature search, Project development, Manuscript writing. MB Literature search, Project development, Project administration, Data collection. ZR Project development, Data analysis, Manuscript editing and revision. MS Literature search, Project administration, Data collection, Data analysis. MH Project administration, Data collection, Data analysis. RD Project administration, Data collection, Data analysis. KMI Project development, Data analysis, Manuscript editing and revision. All authors read and approved the final manuscript.

\section{Funding}

The study was funded by the Scientific Grant Agency of the Ministry of Education of the Slovak Republic under the Contract No. Grant VEGA 1/0873/18, by the National sustainability Program I (NPU I) Nr. LO1503 and Charles University Research Fund (Progres Q39). Kl is partly funded by Project No. CZ.02.1.01/0. 0/0.0/16_019/0000787 "Fighting INfectious Diseases_FIND", awarded by the Ministry of Education, Youth and Sports of the Czech Republic, financed from The European Regional Development Fund.

\section{Availability of data and materials}

The datasets used and/or analyzed during the current study are available from the corresponding author on reasonable request.

\section{Ethics approval and consent to participate}

The study received ethical approval from the relevant ethics committee Slovakia-Ethics Committee L. Pasteur Teaching Hospital in Slovakia (EK 2020/ EK/04024), Due to the anonymous nature of the survey and the ability of participants to elect to respond to the survey or not, the ethics committee did not request a separate consent form because completion and return of the questionnaire was considered an implied consent to participate. Czech Republic_University Hospital in Pilsen (UHP_waiver, April 30, 2020). Slovenia_-University Medical Centre Ljubljana (UMCL_waiver, April 22, 2018). Each NCC kept the hard copy of the completed questionnaires.

\section{Consent for publication}

$$
\text { Not applicable. }
$$

\section{Competing interests}

The authors declare no competing of interest. The funders had no role in the design of the study; in the collection, analyses, or interpretation of data; in the writing of the manuscript, or in the decision to publish the results.

\footnotetext{
Author details

1 Department of Gynecology and Obstetrics, Faculty of Medicine, Safarik's University and L. Pasteur Teaching Hospital in Kosice, SNP Street No. 1, 04001 Košice, Slovak Republic. ${ }^{2}$ Biomedical Center, Faculty of Medicine in Pilsen, Charles University, alej Svobody 80, 30460 Plzeň, Czech Republic. ${ }^{3}$ Department of Obstetrics and Gynecology, University Hospital, Charles University, alej Svobody 80, 30460 Plzeň, Czech Republic. ${ }^{4}$ Division of Gynecology, University Medical Centre Ljubljana, Šlajmerjeva 3, 1525 Ljubljana,
}

Slovenia. ${ }^{5}$ Department of Gynecology and Obstetrics, Faculty of Medicine in Pilsen, Charles University, alej Svobody 80, 30460 Plzeň, Czech Republic.

Received: 31 May 2020 Accepted: 20 October 2020

Published online: 27 October 2020

\section{References}

1. Maher C, Feiner B, Baessler K, Schmid C. Surgical management of pelvic organe prolapse in women. Cochrane Database Syst Rev. 2013;4:CD004014. https://doi.org/10.1002/14651858.CD004014.pub5.

2. Smith FJ, Holman CD, Moorin RE, Tsokos N. Lifetime risk of undergoing surgery for prolapse. Obstet Gynecol. 2010;116:1096-100.

3. Wu JM, Dieter AA, Pate V, Johnson FM. Cumulative incidence of subsequent surgery after stress urinary incontinence and pelvic organ prolapse procedure. Obstet Gynecol. 2017;129:1124-30.

4. Kirby AC, Luber KM, Menefee SA. An update on current and future demand care of pelvic floor disorders in the United States. Am J Obstet Gynecol. 2013;209:584e.1-5.

5. Smazinka M, Kalis V, Havir M, Havelkova L, Ismail KM, Rusavy Z. Obesity and its long-term impact on sacrocolpopexy key outcomes (OBELISK). Int Urogynecol J. 2020;31:1655-62. https://doi.org/10.1007/s00192-01904076-8.

6. Kalis V, Smazinka M, Rusavy Z, Blaganje M, Havir M, Havelkova L, Ismail KM. Laparoscopic sacrocolpopexy as the mainstay management for significant apical pelvic organ prolapse (LAP) study. Eur J Obstet Gynecol Reprod Biol. 2020;244:60-5. https://doi.org/10.1016/j.ejogrb.2019.10.049.

7. Jeppson PC, Sung VW. Hysterectomy for pelvic organ prolapse: indication and techniques. Clin Obstet Gynecol. 2014;57:72-82. https://doi. org/10.1097/GFR.000000000000002.

8. Meriwether KV, Antosh DD, Olivera CK, Kin-Fine S, Balk EM, et al. Uterine preservation vs. hysterectomy in pelvic organ prolapse surgery: a systematic review with meta-analysis and clinical practice guidelines. Am J Obstet Gynecol. 2018;219:129-46.e2. https://doi.org/10.1016/j. ajog.2018.01.018.

9. Rosen DM, Shukla A, Cario GM, Carton MA, Chou D. Is hysterectomy necessary for laparoscopic pelvic floor repair? A prospective study. J Minim Invasive Gynecol. 2008;15:729-34.

10. Bonney $\mathrm{V}$. The principles that should underline all operations for prolapse. J Obstet Gynecol Br Emp. 1934;41:669-83.

11. DeLancey JO. Anatomic aspects of vaginal eversion after hysterectomy. Am J Obstet Gynecol. 1992;166(6 Pt 1):1717-24 (discussion 1724-8). https://doi.org/10.1016/0002-9378(92)91652-o.

12. Ferroni P, Deeple J. Women's subjective experience of hysterectomy. Aust Health Rev. 1996;19:40-55.

13. Yen JY, Chen YH, Long CY, Chang Y, Chen CC, et al. Risk factors for major depressive disorder and the psychological impact of hysterectomy: a prospective investigation. Psychosomatics. 2008;49:137-42.

14. Korbly NB, Kassis NC, Good MM, Richardson ML, Book NM, Yip S, Saguan D, Gross C, Evans J, Lopes WV, Harvie HS, Sung W. Patient preferences for uterine preservation and hysterectomy in women with pelvic organe prolapse. Am J Obstet Gynecol. 2013;209:e1-6.

15. Darwish M, Antalntis E, Taysir-Mohamed T. Psychological outcomes after hysterectomy for benign conditions: a systematic review and metaanalysis. Eur J Obstet Gynecol Reprod Biol. 2014;174:5-19.

16. Frick AC, Barber MD, Paraiso MF, Ridgeway B, Jelovsek JE, Walters MD. Attitudes toward hysterectomy in women undergoing evaluation for uterovaginal prolapse. Female Pelvic Med Reconstr Surg. 2013;19:103-9.

17. van IJsselmuiden MN, Detollenaere RJ, Gerritse MBE, Kluivers KB, Bongers MY, Eijndhoven HWF. Dutch women's attitudes towards hysterectomy and uterus preservation in surgical treatment of pelvic organ prolapse. Eur J Obstet Gynecol Reprod Biol. 2018;220:79-83. https://doi. org/10.1016/j.ejogrb.2017.11.016.

18. Wong K, Jakus-Waldman S, Yazdany T. Patient beliefs regarding hysterectomy in women seeking surgery for pelvic organ prolapse: findings in a predominantly Hispanic population. Female Pelvic Med Reconstr Surg. 2014:20:267-71. 
19. Mandimika CL, Murk W, Mühlhäuser McPencow A, Lake A, Wedderburn T, Collier CH, Connel KA, Guess MK. Knowledge of pelvic floor disorders in a population of community-dwelling women. Am J Obstet Gynecol. 2014;210(2):165.e1-9. https://doi.org/10.1016/j.ajog.2013.10.011.

20. Mandimika CL, Murk W, Mcpencow AM, Lake AG, Miller D, Connel KA, Guess MK. Racial disparities in knowledge of pelvic floor disorders among community-dwelling women. Female Pelvic Med Reconstr Surg 2015;21:287-92. https://doi.org/10.1097/SPV.0000000000000182.

21. Vasconcelos CTM, Firmiano MLV, Oriá MOB, Vasconcelos Neto JA, Saboia DM, Bezerra LRPS. Women's knowledge, attitudes and practise related to urinary incontinence: systematic review. Int Urogynecol J. 2019;30(2):171-80. https://doi.org/10.1007/s00192-018-3759-3.

22. Hartigan SM, Smith AL. Disparities in female pelvic floor disorders. Curr Urol Rep. 2018;19(2):16. https://doi.org/10.1007/s11934-018-0766-3.

23. Chen CCG, Cox JT, Yuan C, Thomaier L, Dutta S. Knowledge of pelvic floor disorders in women seeking primary care: a cross-sectional study. BMC Fam Pract. 2019;20:70. https://doi.org/10.1186/s12875-019-0958-z.

24. La Rosa VL, Ciebiera M, Lin LT, Sleiman Z, Cerentini TM, Lordelo P, Kahramanoglu I, Bruni S, Garzon S, Fichera M. Multidisciplinary management of women with pelvic organ prolapse, urinary incontinence and lower urinary tract symptoms. A clinical and psychological overview. Prz Menopauzalny. 2019;18:184-90. https://doi.org/10.5114/pm.2019.89496.

25. Anglim B, O'Sullivan O, O'Reilly B. How do patients and surgeons decide on uterine preservation or hysterectomy in apical prolapse? Int Urogynecol J. 2018;29:1075-9.

26. Du C, Lee W, Moskowitz D, Lucioni A, Kobashi KC, Lee UJ. I leaked, then I Reddit: experiences and insights shared on urinary incontinence by Reddit users. Int Urogynecol J. 2020;31(2):243-8. https://doi.org/10.1007/ s00192-019-04165-8.

27. Good MM, Korbly N, Kassis NC, Richardson ML, Book NM, Yip S, Saguan D, Gross C, Evans J, Harvie HS, Sung V. Prolapse-related knowledge and attitudes toward the uterus in women with pelvic organe prolapse symptoms. Am J Obstet Gynecol. 2013;209(481):e1-6.

28. Costantini E, Porena M, Lazzeri M, Mearini L, Bini V, Zucchi A. Changes in female sexual function after pelvic organ prolapse repair: role of hysterec tomy. Int Urogynecol J. 2013;24:1481-7.
29. Hemming C, Constable L, Goulao B, Kilonzo M, Boyers D, Elders A, Cooper K, Smith A, Freeman R, Breeman S, McDonald A, Hagen S, Montgomery I, Norrie J, Glazener C. Surgical interventions for uterine prolapse and for vault prolapse: the two VUE RCTs. Health Technol Assess. 2020;24:1-220. https://doi.org/10.3310/hta24130.

30. Maher CM, Feiner B, Baessler K, Glazener CMA. Surgical management of pelvic organ prolapse in women: the updated summary version Cochrane review. Int Urogynecol J. 2011;22:1445-57. https://doi. org/10.1007/s00192-011-1542-9.

31. Gracia M, Perelló M, Bataller E, Espuña M, Parellada M, Genís D, et al. Comparison between laparoscopic sacral hysteropexy and subtotal hysterectomy plus cervicopexy in pelvic organ prolapse: a pilot study. Neurourol Urodyn. 2015;34:654-8. https://doi.org/10.1002/nau.22641.

32. Saliba E, Nisolle M, Tchente C, De Landsheere L. Doit-on réaliser systématiquement une hystérectomie subtotale dans le cadre d'une promontofixation cœlioscopique? [EN] Do we need to perform systematic supracervical hysterectomy during laparoscopic sacrocolpopexy? Gynécologie Obs Fertil Sénologie. 2019;47:549-54. https://doi.org/10.1016/j. gofs.2019.04.007.

33. Pan K, Cao L, Ryan NA, Wang Y, Xu H. Laparoscopic sacral hysteropexy versus laparoscopic sacrocolpopexy with hysterectomy for pelvic organ prolapse. Int Urogynecol J. 2016;27:93-101. https://doi.org/10.1007/ s00192-015-2775-9.

34. Illiano E, Giannitsas K, Costantini E. Comparison between laparoscopic sacrocolpopexy with hysterectomy and hysteropexy in advanced urogenital prolapse. Int Urogynecol J. 2020;31:2069-74. https://doi. org/10.1007/s00192-020-04260-1.

35. Kalis V, Rusavy Z, Ismail KM. Laparoscopic sacrohysteropexy: the Pilsner modification. Int Urogynecol J. 2020;31:1277-80. https://doi.org/10.1007/ s00192-019-04150-1.

\section{Publisher's Note}

Springer Nature remains neutral with regard to jurisdictional claims in published maps and institutional affiliations.
Ready to submit your research? Choose BMC and benefit from:

- fast, convenient online submission

- thorough peer review by experienced researchers in your field

- rapid publication on acceptance

- support for research data, including large and complex data types

- gold Open Access which fosters wider collaboration and increased citations

- maximum visibility for your research: over $100 \mathrm{M}$ website views per year

At BMC, research is always in progress.

Learn more biomedcentral.com/submissions 